\title{
Huge Recalcitrant Warts Treated with Pulse Dye Laser after Conventional Therapies and Others Destructive Physical Modalities Failed
}

\author{
Nuno Menezes, Paulo Varela, Rita Guedes, Inês Leite, Armando Baptista \\ Serviço de Dermatologia e Venereologia do Centro Hospitalar de Vila Nova de Gaia, Vila Nova de Gaia, Portugal. \\ Email: nuno.menezes.dermatologia@gmail.com
}

Received March $17^{\text {th }}, 2011$; revised May $3^{\text {rd }}, 2011$; accepted June $15^{\text {th }}, 2011$.

\begin{abstract}
Cutaneous infections with the human papilloma virus, despite being almost always asymptomatic, can induce slowgrowing lesions knowed as warts that can remain subclinical for long periods of time. There are several therapeutical options namely keratolytics, retinoids, imiquimod, cryotherapy, electrosurgery, lasers and classic surgery, but none has antiviral effects. We describe the case of a patient with large warts located on the dorsal surface of the right hand, treated with cryotherapy, $\mathrm{CO}_{2}$ laser and topical imiquimod having either no clinical response or quick relapse. Treatment with PDL was started and after 13 sessions, the patient was without lesions, with a good cosmetic result and so far without relapse. This case report is relevant to us and deserves to be published because of the size of the lesions and the great response to PDL despite all the failures with the other treatments.
\end{abstract}

Keywords: Pulse Dye Laser, Recalcitrant Warts

\section{Introduction}

Warts are a common dermatologic complaint, with an estimated incidence of $10 \%$ in children and young adults, being an important motive for dermatologic consultation. They are benign epithelial neoplasms of the skin and mucous membranes resulting from human papillomavirus infection.

Despite possible spontaneous remission, their aesthetic or functional induced impairment, together with their contagious nature, makes treatment necessary.

Therapeutic approaches include immunotherapy agents, keratolytic agents, cytotoxic agents, biological modifiers and physical destructive modalities such as curettage, electrocautery, chemical cautery, cryotherapy, surgical excision and some laser methods [1-4].

\section{Clinical Case}

We describe the case of a patient, otherwise healthy, with large warts located on the dorsal surface of the right hand and fingers, with a two years evolution. He had a great number of lesions, the biggest one having $13 \times 9 \mathrm{~cm}$. He was a manual worker and the lesions caused him a lot of discomfort at work besides aesthetic problems, so he wanted to get ride of the problem.
We started treatment with cryotherapy with two 15second freeze-thaw cycles that were repeated after 4 weeks. Four sessions were performed with minor response. Patient started to apply imiquimod $5 \mathrm{x} /$ week for 6 weeks, again without sustained response. It was decided to perform a destruction of the lesions with the $\mathrm{CO}_{2}$ laser, which implied a 2 months downtime period after the procedure. After full cicatrisation of the lesions, rapid relapse of the lesions was noticed (Figure 1).

Treatment with a pulse dye laser was performed (PDL, $585 \mathrm{~nm}$, Candela PhotoGenica V-Star), with a 7-mm spot size at $9 \mathrm{~J} / \mathrm{cm}^{2}$. Each lesion received 2 pulses with 1 to 2 $\mathrm{mm}$ overlap and $2 \mathrm{~mm}$ border of normal appearing skin was also treated. During the treatment the freezing device was kept at level 3/7. Increments of energy between the sessions were performed according to the lesions response and the interval between the sessions was 5 to 8 weeks. After 4 sessions a good response was obtained with an almost complete clearance of the lesions (Figure 2), with a total of 13 sessions necessary to have complete response (Figure 2). The fluences used are represented on Table 1. No relapse occurred so far.

\section{Discussion}

There are an estimated 4 million visits to dermatologists 


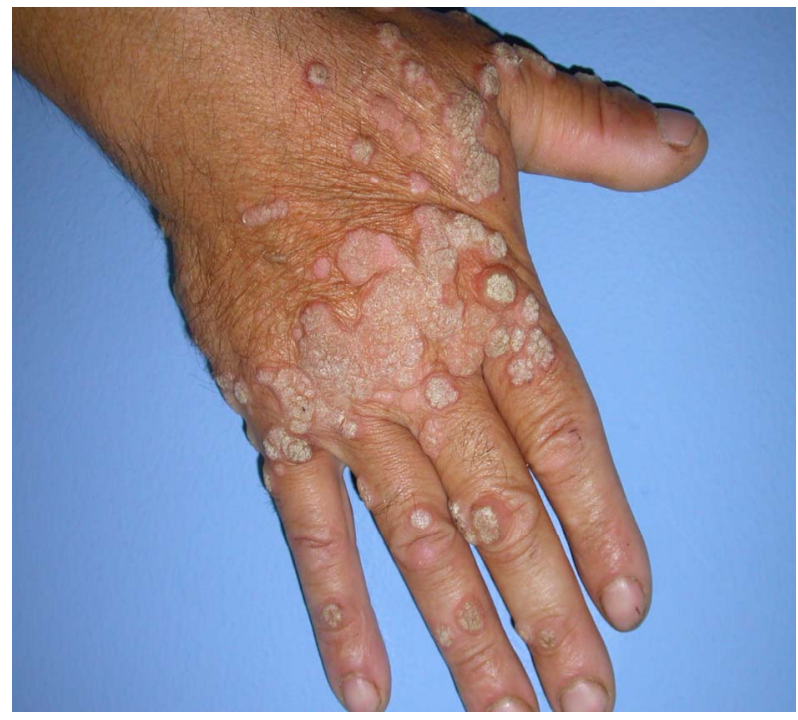

Figure 1. Lesions before PDL.

Table 1. PDL parameters use in the sessions.

\begin{tabular}{cccccc}
\hline $\begin{array}{c}\text { Ses- } \\
\text { sions }\end{array}$ & Date & $\begin{array}{c}\text { Energy } \\
\left(\mathbf{J} / \mathbf{c m}^{2}\right)\end{array}$ & $\begin{array}{c}\text { Spot } \\
(\mathbf{m m})\end{array}$ & $\begin{array}{c}\text { Pulse } \\
(\mathbf{m s})\end{array}$ & $\begin{array}{c}\text { Wave- } \\
\text { lenght } \\
(\mathbf{n m})\end{array}$ \\
\hline 1 & $\mathbf{0 1 / 1 0 / 0 4}$ & 9 & 7 & $\mathbf{0 . 5}$ & 585 \\
2 & $\mathbf{0 3 / 1 1 / 0 4}$ & 10.5 & 7 & 0.5 & 585 \\
3 & $\mathbf{0 2 / 1 2 / 0 4}$ & 11.6 & 7 & 0.5 & 585 \\
4 & $12 / 01 / 05$ & 5.9 & 10 & 0.5 & 585 \\
5 & $16 / 02 / 05$ & 9 & 10 & 0.5 & 585 \\
6 & $23 / 03 / 05$ & 8.7 & 10 & 0.5 & 585 \\
7 & $28 / 04 / 05$ & 9 & 10 & 0.5 & 585 \\
8 & $30 / 05 / 05$ & 12 & 7 & 0.5 & 585 \\
9 & $29 / 06 / 05$ & 15.7 & 7 & 0.5 & 585 \\
10 & $05 / 08 / 05$ & 16.9 & 7 & 0.5 & 585 \\
11 & $16 / 09 / 05$ & 16.9 & 7 & 0.5 & 585 \\
12 & $19 / 10 / 05$ & 17.4 & 7 & 0.5 & 585 \\
13 & $18 / 11 / 05$ & 18 & 7 & 0.5 & 585 \\
\hline
\end{tabular}

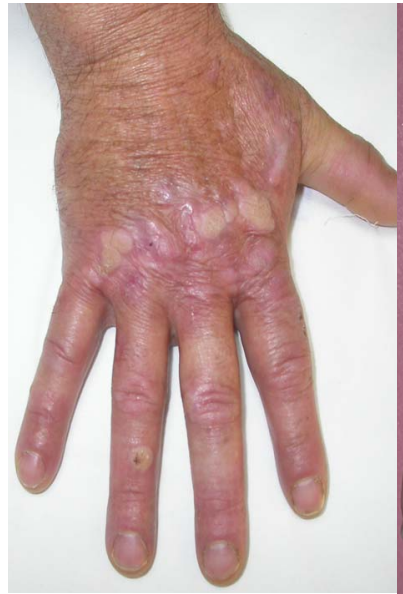

(a)

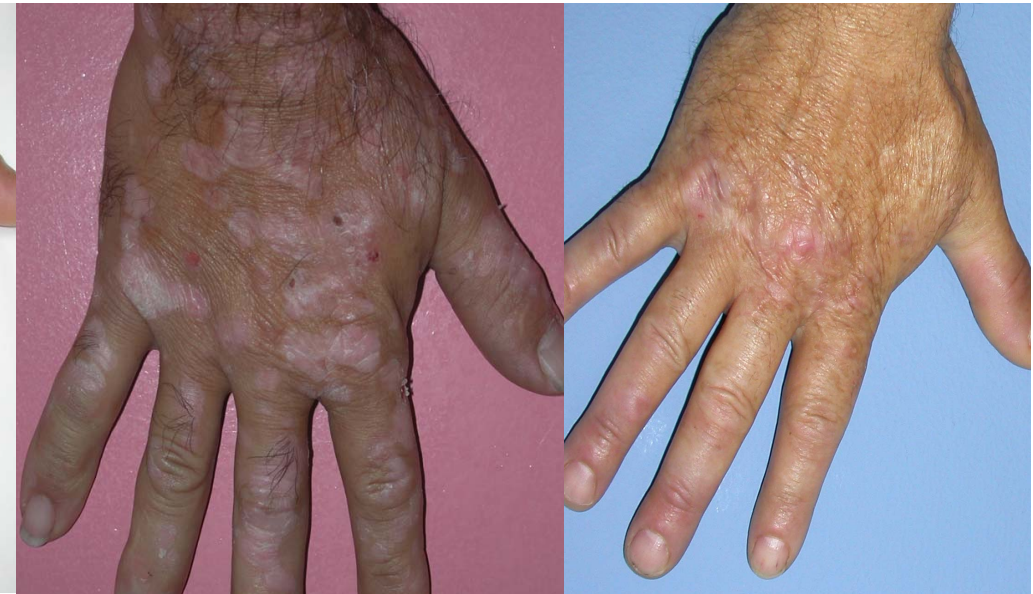

(b) (c)

Figure 2. (a) Lesions after 4 sessions of treatment with PDL; (b) 8 sessions; and (c) 13 sessions.

for nonvenereal warts in the US [1] each year and although there are several different approaches in how to treat warts none of them have antiviral effect $[2,3]$. Sometimes it is necessary to use more than one therapy to achieve a complete response. As spontaneous remis- sion can occur, a wait and see approach can sometimes be used, but normally patient seek medical help, due to aesthetics and functional impairment.

In our department cryotherapy or topics (keratolytics) are used as a first line approach and in case of failure treatment with the PDL is tried. In this patient due to the size of the lesions, we decided to vaporize it first with the $\mathrm{CO}_{2}$ laser hoping for a complete response after the procedure, because the patient wanted fast results.

The efficacy of the $585 \mathrm{~nm}$ PDL in treating warts is well demonstrated by some authors [5-10]. The mechanism of action of this laser is still unclear, but it may be the result of intense heating of the dermal vessels, blocking the blood supply to the wart and inducing a keratinocyte necrosis $[11,12]$. This theory is based on the presence of dilated and congested vessels at the base of most warts and the selective phototermolysis induced by this type of lasers $[13,14]$. Light microscopic evaluation of treated areas immediately after treatment and at 1,6 and 13 days after treatment shows agglutinated erythrocytes in the papillary vessels, with subsequent thrombosis and endothelial and keratinocyte necrosis $[5,13,14]$. This kind of therapy leads to fewer side-effects than more conventional therapies regarding blood loss, infection, pain, scarring and downtime, especially when compared with 
the $\mathrm{CO}_{2}$ laser $[5,15,16]$. Our patient needed a 2 month downtime period after the $\mathrm{CO}_{2}$ treatment and didn't need to stop at all between the PDL treatments.

Studies to access PDL efficacy to treat warts classified them in simple or recalcitrant, the last ones being lesions that exist for more than 2 years and had had at least one or two others therapies $[5,8,15]$. Akarsu et al. observed that recalcitrant warts, despite needing more treatments, have a better response rate than simple ones [17].

Our case represents another example of success when treating recalcitrant warts with the PDL, despite the great number of sessions and higher fluences used to achieve a complete response. We performed 13 sessions because complete remission of the lesions was the goal. During treatment the spot size was changed due to a problem in the mirrors of the $7 \mathrm{~mm}$ hand piece that became again used after it was solved. This treatment didn't lead to any relevant side-effect not even hipo/hiperpigmentation which are common when using PDL.

This paper supports the recent report by Passeron et al. about the need to use higher fluences, pulse stacking and shorter intervals between the treatments when treating palmo-plantar warts [12].

Some authors believe that before laser treatments, the surface of the wart should be peeled with a blade, so that the light can penetrate deeper but so far no study was able to prove this [17].

This report shows that PDL can be therapeutically effective in recalcitrant warts when other less expensive therapies failed, particularly if high fluences are used and pulse stacking is performed with less than 8 weeks interval between treatments.

\section{REFERENCES}

[1] M. W. Cobb, "Human Papillomavirus Infection," Journal of the American Academy of Dermatology, Vol. 22, No. 4, 1990, pp. 547-566. doi:10.1016/0190-9622(90)70073-Q

[2] B. Berman and A. Weinstein, "Treatment of Warts," Dermatologic Therapy, Vol. 13, No. 3, 2000, pp. 290-304. doi:10.1046/j.1529-8019.2000.00031.x

[3] A. Torrelom "What's New in the Treatment of Viral Warts in Children," Pediatric Dermatology, Vol. 19, No. 3, 2002, pp. 191-199. doi:10.1046/j.1525-1470.2002.00081.x

[4] E. Lukasiewicz, J. Martel, J. C. Roujeau and A. Flahault, "La Dermatologie Lebérale en France Métropolitaine en 2000,"Annales de Dermatologie et de Vénéréologie, Vol. 129, No. 11, 2002, pp. 1261-1265

[5] O. T. Tan, R. M. Hurwitz and T. J. Stafford, "Pulsed Dye Laser Treatment of Recalcitrant Verrucae: A Preliminary Report," Lasers in Surgery and Medicine, Vol. 13, No. 1, 1993, pp. 127-137. doi:10.1002/1sm.1900130120

[6] A. N. B. Kauvar, D. H. McDaniel and R. G. Geronemus,
"Pulsed Dye Laser Treatment of Warts," Archives of Family Medicine, Vol. 4, No. 12, 1995, pp. 1035-1040. doi:10.1001/archfami.4.12.1035

[7] A. Jain and G. S. Storwick, "Effectiveness of the $585 \mathrm{~nm}$ Flashlamp-Pulsed Tunable Dye Laser (PTDL) for Treatment of Plantar Verrucae," Lasers in Surgery and Medicine, Vol. 21, No. 5, 1997, pp. 500-505.

doi:10.1002/(SICI)1096-9101(1997)21:5<500::AID-LSM 13>3.0.CO;2-C

[8] E. Jacobsen, R. McGraw and S. McCagh, "Pulsed Dye Laser efficacy as Initial Therapy for Warts and Against Recalcitrant Verrucae," Cutis, Vol. 59, No. 4, 1997, pp. 206-208.

[9] C. Wu, S. Langan, M. Kilmurray, D. Lawlor and R. Watson, "Efficacy of Pulsed-Dye Laser for Viral Warts-An Internal Audit," The Irish Medical Journal, Vol. 96, No. 3, 2003, pp. 82-83.

[10] B. S. Ross, V. J. Levine, K. Nehal and R. Ashinoff, "Pulsed Dye Laser Treatment of Warts: An Update," Dermatologic Surgery, Vol. 25, No. 5, 1999, pp. 377-380. doi:10.1046/i.1524-4725.1999.07165.x

[11] K. J. Robson, N. M. Cunningham, K. I. Kruzan, D. S. Patel, C. D. Kreiter, M. J. O'Donnell and C. J. Arpey, "Pulsed-Dye Laser versus Conventional Therapy in the Treatment of Warts: A Prospective Randomized Trial," Journal of the American Academy of Dermatology, Vol. 43, No. 2, 2000, pp. 275-280. doi: $10.1067 / \mathrm{mjd} .2000 .106365$

[12] T. Passeron, K. Sebban, F. Mantoux, E. Fontas, J. P. Lacour and J. P. Ortonne, "Traitement des Verrues Palmo-Plantaires par le Laser à Colorant Pulsé à 595 nm: Etude Randomisée em Simple Insu Contre Placebo," Annales de Dermatologie et de Vénéréologie, Vol. 134, No. 2, 2007, pp. 135-139. doi:10.1016/S0151-9638(07)91604-X

[13] D. Elder, R. Elenitsas, C. Jaworsky, B. Johnson Jr., "Lever's Histopathology of the Skin," 8th Edition, J. B. Lippincott, Philadelphia, 1997, pp. 578-582.

[14] R. R. Anderson and J. A. Parrish, "Selective Photo-thermolysis: Precise Microsurgery by Selective Absorption of Pulsed Radiation," Science, Vol. 220, No. 4596, 1983, pp. 524-527. doi:10.1126/science.6836297

[15] S. Sood and G. J. Hruza, "Treatment of Verruca Vulgaris and Condyloma Acuminatum with Lasers," Dermatologic Surgery, Vol. 13, No. 1, 2000, pp. 90-101. doi:10.1046/j.1529-8019.2000.00010.x

[16] H. Vargas, C. R. Hove, M. L. Dupree and E. F. Williams, "The Treatment of Facial Verrucae with Pulsed Dye Laser," The Laryngoscope, Vol. 112, No. 9, 2002, pp. 15731576. doi:10.1097/00005537-200209000-00007

[17] S. Akarsu, T. Ilknur, M. Demirtaşoğlu and Ş Özkan, "Verruca Vulgaris: Pulsed Dye Laser Therapy Compared with Salicylic Acid + Pulsed Dye Laser Therapy," Journal of the European Academy of Dermatology and Venereology, Vol. 20, No. 8, 2006, pp. 936-940. doi:10.1111/j.1468-3083.2006.01679.x 